\title{
Magnetic resonance imaging of intraocular foreign bodies
}

\author{
THOMAS HARDIE WILLIAMSON," FRANCIS W SMITH, \\ AND JOHN V FORRESTER ${ }^{1}$ \\ From the Departments of: Ophthalmology and ${ }^{2}$ Radiology, Aberdeen Medical School, Aberdeen
}

SUMMARY Magnetic resonance imaging was performed with a low field strength scanner $(0 \cdot 08$ tesla) on 15 bovine eyes into which had been inserted various magnetic and non-magnetic foreign bodies. The precise location of the foreign bodies was determined by dissection. Magnetic resonance imaging was accurate in locating 11 of the 13 non-magnetic foreign bodies in this study. In addition a further five bovine eyes containing 10 - to 20 - $\mathrm{mm}$ long steel needles were scanned and dissected. No ocular damage attributable to movement of the foreign bodies could be seen.

The identification and localisation of intraocular foreign bodies relies primarily on soft tissue $\mathrm{x}$-ray. Computerised tomography scanning has been shown to be useful but has some limitations. ${ }^{1}$ It may be inadequate for some radiolucent foreign bodies or those adjacent to the sclera. Ultrasound is also useful, especially if the foreign body is large or for visualising the complications of penetrating injuries such as retinal detachment or vitreous haemorrhage. However, ultrasonic transducers are frequently not suitable for study of the acutely injured eye, because they require either direct contact with the eye or indirect coupling via a waterbath system.

The purpose of this study was to determine whether foreign bodies could be usefully detected in ocular tissue by magnetic resonance imaging. Vitreous haemorrhage and intravitreal air were imaged for comparison. In addition the eyes were inspected by dissection to determine any damage resulting from movement of the foreign bodies during the scanning technique.

\section{Material and methods}

\section{FOREIGN BODIES}

A variety of organic and metallic foreign bodies were used in this study (Table 1). One copper, two steel, two aluminium, and two lead intraocular metallic foreign bodies were imaged and varied in size from $2 \times 1 \times 1 \mathrm{~mm}$ to $5 \times 3 \times 2 \mathrm{~mm}$. Two fragments of soft

Correspondence to Dr $\mathbf{H}$ Williamson, Department of Ophthalmology, Addenbrookes Hospital, Cambridge CB1 2NU. wood, two of laminated siliconised glass (windscreen glass), one fragment of graphite (pencil lead), one polyethylene, and two gravel fragments were scanned. The smallest was $3 \times 2 \times 2 \mathrm{~mm}$ and the largest $5 \times 3 \times 3 \mathrm{~mm}$.

In addition five eyes which each had a single 10- or 20-mm long steel needle inserted were scanned and dissected.

METHOD OF INSERTION

The foreign bodies were inserted into fresh bovine

Table 1 Intraocular foreign bodies inserted into bovine eyes

\begin{tabular}{|c|c|c|c|}
\hline & Position & Size & $\begin{array}{l}\text { Detection: } \\
\text { yes }(Y) \text { or } \\
\text { no }(N)\end{array}$ \\
\hline Aluminium & $\begin{array}{l}\text { post. choroid } \\
\text { ant. vitreous }\end{array}$ & $\begin{array}{l}5 \times 3 \times 2 \\
4 \times 3 \times 0 \cdot 1\end{array}$ & $\begin{array}{l}\mathbf{Y} \\
\mathbf{Y}\end{array}$ \\
\hline Copper & ant. vitreous & $3 \times 2 \times 0.25$ & $\mathbf{Y}$ \\
\hline Lead & $\begin{array}{l}\text { post. choroid } \\
\text { ant. vitreous }\end{array}$ & $\begin{array}{l}2 \times 1 \times 1 \\
2 \times 1 \times 1\end{array}$ & $\begin{array}{l}\mathbf{N} \\
\mathbf{Y}\end{array}$ \\
\hline Glass & $\begin{array}{l}\text { post. choroid } \\
\text { ant. vitreous }\end{array}$ & $\begin{array}{l}3 \times 2 \times 2 \\
3 \times 2 \times 4\end{array}$ & $\begin{array}{l}\mathbf{N} \\
\mathbf{Y}\end{array}$ \\
\hline Graphite & post. choroid & $3 \times 2 \times 2$ & $\mathbf{Y}$ \\
\hline Polythene & post. vitreous & $3 \times 2 \times 1$ & $\mathbf{Y}$ \\
\hline Steel & $\begin{array}{l}\text { post. choroid } \\
\text { post. choroid }\end{array}$ & $\begin{array}{l}3 \times 3 \times 0 \cdot 2 \\
3 \times 4 \times 0 \cdot 2\end{array}$ & $\begin{array}{l}\text { Artefact } \\
\text { Artefact }\end{array}$ \\
\hline Gravel & $\begin{array}{l}\text { post. choroid } \\
\text { ant. vitreous }\end{array}$ & $\begin{array}{l}3 \times 2 \times 3 \\
5 \times 3 \times 3\end{array}$ & $\begin{array}{l}\mathrm{Y} \\
\mathrm{Y}\end{array}$ \\
\hline Soft wood & $\begin{array}{l}\text { post. choroid } \\
\text { ant. vitreous }\end{array}$ & $\begin{array}{l}4 \times 2 \times 2 \\
4 \times 2 \times 2\end{array}$ & $\begin{array}{l}\mathbf{Y} \\
\mathbf{Y}\end{array}$ \\
\hline Controls & $\begin{array}{l}\text { Intravitreal air } \\
\text { Intravitreal haemorrhage } \\
\text { Wound only } \\
\text { Wound and suprachoroidal } \\
\text { Haelonid }\end{array}$ & & \\
\hline
\end{tabular}


eyes through a triangular scleral flap at the posterior pole with microforceps to place the foreign bodies in the suprachoroidal space or the vitreous gel. To avoid the introduction of air the foreign bodies were inserted into the suprachoroidal space under sodium hyaluronate (Healonid).

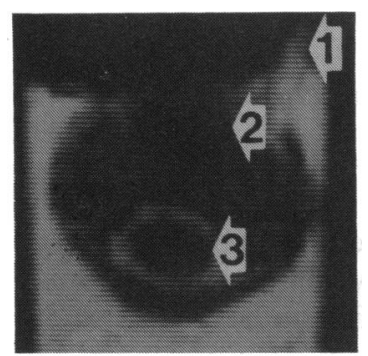

Fig: 1

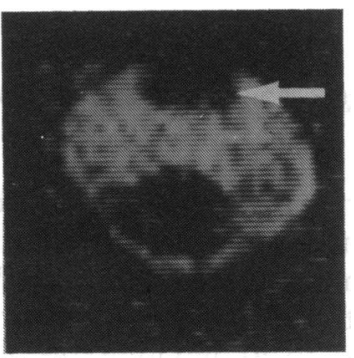

Fig. 2

Two control eyes were similarily operated upon but without the insertion of foreign bodies to determine whether any scanning artefact was induced by the wound or the presence of Healonid. $0.5 \mathrm{ml}$ of human blood was injected into the vitreous by a 23 gauge needle through the pars plana into the vitreous

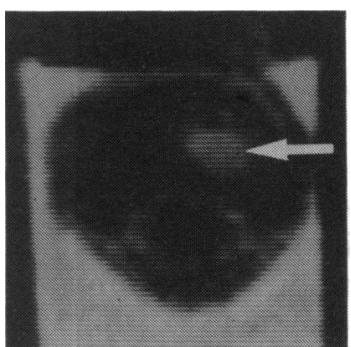

Fig. 3

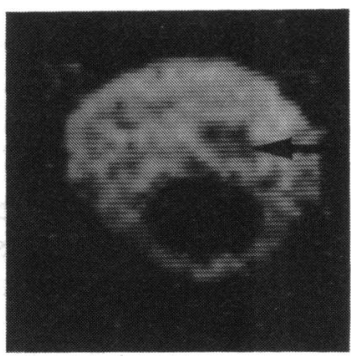

Fig. 4

Fig. 1 A proton density image of a bovine eye with $1.0 \mathrm{ml}$ of intravitreal air. Arrow 1 shows the optic nerve, arrow 2 the intravitreal air, arrow 3 the lens. Fig. 2 An inversion recovery image of $1.0 \mathrm{ml}$ of intravitreal air (arrow). Fig. 3 A proton density image of $0.5 \mathrm{ml}$ of intravitreal haemorrhage (arrow). Fig. 4 An inversion recovery image of $0.5 \mathrm{ml}$ of intravitreal haemorrhage (arrow).

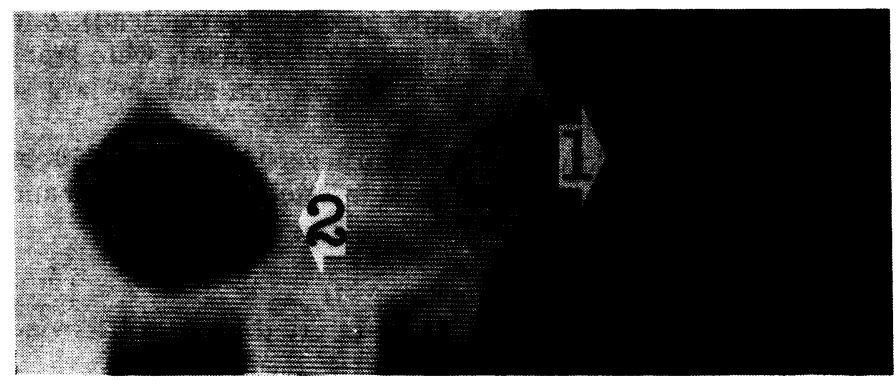

Fig. 5 The TI weighted image of the artefact from a ferromagnetic foreign body. Arrow 1 shows the position of the globe with a $3 \times 3 \times 0.2 \mathrm{~mm}$ steel foreign body, but the image of the globe is obscured by the effect of the presence of only a small steel foreign body. Arrow 2 shows a globe with a $4 \times 2 \times 2 \mathrm{~mm}$ soft wood fragment for comparison.

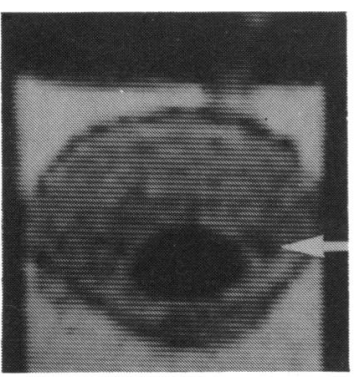

Fig. 6

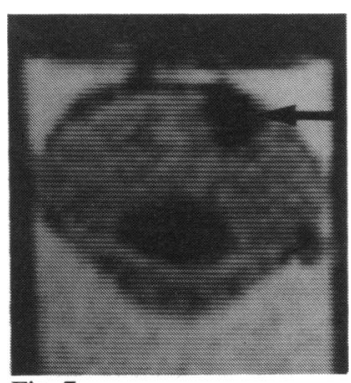

Fig. 7

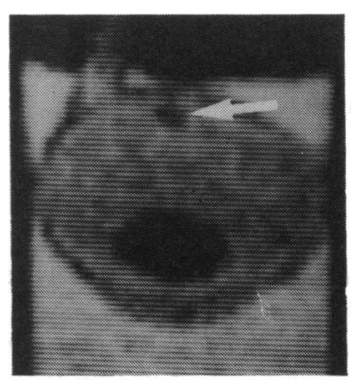

Fig. 8

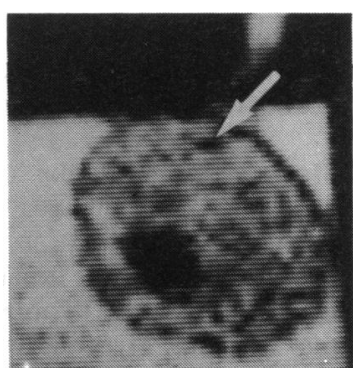

Fig. 9

Fig. 6 A T1 weighted image of an aluminium fragment $(4 \times 3 \times 0.1 \mathrm{~mm})$ in the anterior vitreous (arrow). Fig. 7 A T1 weighted image of a gravel fragment $(3 \times 2 \times 2 \mathrm{~mm})$ in the posterior suprachoroidal spaces (arrow). Fig. 8 A T1 weighted image of a soft wood fragment $(4 \times 2 \times 2 \mathrm{~mm})$ in the posterior suprachoroidal space (arrow). Fig. 9 A T1 weighted image of a high density polyethylene foreign body $(3 \times 2 \times 1 \mathrm{~mm})$ in the posterior vitreous (arrow). 
gel. Similarly $1.0 \mathrm{ml}$ of air was injected into the vitreous gel of another eye.

MAGNETIC RESONANCE SCANNING TECHNIQUE The eyes were immersed in a bath of copper sulphate in a Perspex container which provided a background intensity against which the globe could be visualised. The globe was imaged transaxially with a four-coil air cored resistive magnet of $0.08 \mathrm{~T}$ main field strength. The imager has a resonant frequency for hydrogen of 3.4 megaHz. An interleaved pulse sequence consisting of $90^{\circ}$ radiofrequency pulses every $1000 \mathrm{~ms}$ with alternate pulses preceded by $180^{\circ}$ inversion was used. From the sequence information it is possible to display a saturation recovery image (proton density), inversion recovery image, $\mathrm{T} 1$ calculated image, $\mathrm{T} 1$ weighted image (image formed by the subtraction of two interleaved signals which gives anatomically detailed images with T1 weighting. ${ }^{23} 8 \mathrm{~mm}$ slice thicknesses were taken with a surface coil.

\section{METHOD OF LOCALISATION}

After being imaged the eyes were dissected by removal of the anterior globe by incision through the pars plana. The location of the foreign body was noted in relation to the optic nerve and the wound site and compared with the magnetic resonance images. Any change in the position of the foreign body or damage to the intraocular structures was noted.

\section{Results}

Control eyes showed no significant artefact from the wound site or the injection of Haelonid. $1.0 \mathrm{ml}$ of injected air appeared on scan as an area of low signal on proton density (Fig. 1) and inversion recovery (Fig. 2). Fresh vitreous haemorrhage was seen as an area of high proton density (Fig. 3) and low inversion recovery (Fig. 4). Steel foreign bodies caused a large artefact which obscured all detail of the globe despite the small size of the foreign bodies used (Fig. 5).

The other foreign bodies as small as $2 \times 1 \times 1 \mathrm{~mm}$ were easily visualised as low intensity defects on inversion recovery, proton density, and T1 weighted images (Figs. 6, 7, 8, 9). They were seen most clearly on the $\mathrm{T} 1$ weighted images.

In two cases the foreign bodies were not detected, when a piece of glass and a lead foreign body were placed in the suprachoroidal space. Graphite gave a small artefact which did not obscure detail of the globe significantly.

It was not possible to distinguish the different materials by this scanning technique.

No change in the position of the foreign bodies or damage to the intraocular structures was found, including those with large ferromagnetic foreign bodies (needles). The retinae were damaged only at the site of insertion of the foreign bodies.

\section{Discussion}

The present study has shown that magnetic resonance imaging is capable of detecting small nonferromagnetic foreign bodies in ocular tissue. Even at the low field strength used the foreign bodies were plainly visible in 11 of the 13 eyes and localisation was possible. They are readily differentiated from other ocular tissues. However, as with computed tomography scanning, foreign bodies close to the sclera are more difficult to detect. In this series two of the six suprachoroidal foreign bodies were not detected, whereas similarly sized foreign bodies in the vitreous gel were detectable. Sclera gives low proton density and inversion recovery signals similar to the foreign body characteristics and may therefore obscure foreign body detail.

Vitreous haemorrhage resulting from a penetrating injury from an intraocular foreign body is unlikely to reduce foreign body detection. In this study the characteristics of haemorrhage on magnetic resonance imaging were shown to differ from those of foreign body material (a low T1 and high proton density signal). In addition the $\mathrm{T} 1$ signal will increase as the vitreous haemorrhage ages..$^{45}$ Intraocular air may be confused but is unlikely to be present unless vitreoretinal surgery has been performed.

Magnetic resonance scanning using more modern scanners of higher field strength is likely to give higher resolution images and allow thinner slices, ${ }^{67}$ which would improve detection and localisation. However, there is a district risk of torsional forces being applied to the ferromagnetic foreign body, thereby causing intraocular complications. ${ }^{8}$ Indeed ferromagnetic foreign bodies have been shown to move in gelatin and cause retinal tear, dialysis, and detachment in rabbits after magnetic resonance imaging with high field strength systems. ${ }^{9}$ One case of vitreous haemorrhage has been described following scanning with a $0.35 \mathrm{~T}$ imager of a ferromagnetic foreign body. ${ }^{10}$ Reports of magnetic resonance imaging of foreign bodies elsewhere in the human body - for example, intracranial aneurysm clipshave not included significant complications from the technique. ${ }^{1112}$

In this study the technique caused no injury to the intraocular tissues at the low field strength $(0.08 \mathrm{~T})$ used and is considered to be safe. However, at the field strengths of more modern scanners it is likely to be too hazardous a technique to be a viable alterative to conventional $x$-ray, ultrasound, and CT scanning unless the magnetic properties of the foreign body are known. 


\section{References}

1 Topilow HW, Ackerman AL, Zimmerman RD. Limitations of computurised tomography in the localisation of intraocular foreign bodies. Ophthalmology 1984; 91 : 1086-91.

2 Edelstein WA, Hutchinson JMS, Johnson G, Redpath T. Spin warp nuclear magnetic resonance imaging applications to whole body imaging. Phys Med Biol 1980; 25: 751-6.

3 Hutchison JMS, Edelstein WA, Johnson G. A whole body nuclear magnetic resonance imaging machine. Journal of Physics $E$ (Scientific Instruments). 1980; 13: 947-53.

4 Haik BG, Saint Louis L, Smith ME, et al.. Magnetic resonance imaging in the evaluation of leukocoria. Ophthalmology 1985; 92: $1133-42$.

5 Mafee F, Peyman GA, Grisolano JE, et al. . Malignant uveal melanoma and simulating lesions: magnetic resonance imaging evaluation. Radiology 1986; 160: 773-80.

6 Schneck JF, Foster TH, Edelstein WA, et al. Improved magnetic resonance imaging of the orbit at $1.5 \mathrm{~T}$ with surface coils. AJR 1985; 144: 193-6.

7 Zheullin JD, Thompson JT, Shofner RS. The safety of magnetic resonance imaging with intra-orbital metallic objects after retinal detachment surgery or trauma. Am J Ophthalmol 1987; 103: 831 .

8 New PFJ, Rosen BR, Brady TJ, et al. Potential hazards and artifacts of ferromagnetic surgical and dental material and deviation in the nuclear magnetic resonance imaging. Radiology 1983; 147: 139-48.

9 Lagouros PA, Langer BG, Peyman GA, Mafee MF, Spigos DG, Grisolano $J$. Magnetic resonance imaging and intraocular foreign bodies. Arch Ophthalmol 1987; 105: 551-3.

10 Kelly WM, Paglen PG, Pearson JA, San Diego AG, Solaman MA. Ferromagnetism of intraocular foreign body causes unilateral blindness after magnetic resonance study. Am J Neuroradiol 1986; 7: 243-5.

11 Davis PL, Crookes L, Arakawa M, McRee R, Kauffman L, Margulis AR. Potential hazards in nuclear magnetic resonance imaging. $A J R$ 1981; 137: 857-60.

12 Laakman RW, Kaufmann B, Han JS, et al. Magnetic resonance imaging in patients with metallic implants. Radiology 1985; 157: $711-4$.

Accepted for publication 2 November 1988. 